\section{(6) OPEN ACCESS}

\title{
Risk factors for persistence of lower respiratory symptoms among community members exposed to the 2001 World Trade Center terrorist attacks
}

\author{
Hannah T Jordan, ${ }^{1}$ Stephen M Friedman, ${ }^{1}$ Joan Reibman, ${ }^{2}$ Roberta M Goldring, ${ }^{2}$ \\ Sara A Miller Archie, ${ }^{1}$ Felix Ortega, ${ }^{1}$ Howard Alper, ${ }^{1}$ Yongzhao Shao, ${ }^{2}$ Carey B Maslow, \\ James E Cone, ${ }^{1}$ Mark R Farfel, ${ }^{1}$ Kenneth I Berger ${ }^{2}$
}

\begin{abstract}
- Additional material is published online only. To view please visit the journal online (http://dx.doi.org/10.1136/ oemed-2016-104157)

${ }^{1}$ World Trade Center Health Registry, New York City Department of Health and Mental Hygiene, New York, New York, USA

${ }^{2}$ Department of Medicine, New York University School of Medicine, New York, New York, USA
\end{abstract}

\section{Correspondence to} Dr Hannah T Jordan, Deputy Medical Director, World Trade Center Health Registry; New York City Department of Health and Mental Hygiene; 125 Worth Street, 10th floor, CN 6W; New York, NY 10013, USA; hjordan1@health.nyc.gov

Received 21 October 2016 Revised 9 February 2017 Accepted 15 February 2017

Published Online First 23 March 2017

\section{ABSTRACT}

Objectives We studied the course of lower respiratory symptoms (LRS; cough, wheeze or dyspnoea) among community members exposed to the 9/11/2001 World Trade Center (WTC) attacks during a period of 12-13 years following the attacks, and evaluated risk factors for LRS persistence, including peripheral airway dysfunction and post-traumatic stress disorder (PTSD).

Methods Non-smoking adult participants in a case-control study of post-9/11-onset LRS (exam 1, 2008-2010) were recruited for follow-up (exam 2, 2013-2014). Peripheral airway function was assessed with impulse oscillometry measures of $R_{5}$ and $R_{5-20}$. Probable PTSD was a PTSD checklist score $\geqq 44$ on a 2006-2007 questionnaire.

Results Of 785 exam 1 participants, 545 (69\%) completed exam 2. Most (321, 59\%) were asymptomatic at all assessments. Among 192 participants with initial LRS, symptoms resolved for 110 (57\%) by exam 2, 55 (29\%) had persistent LRS and 27 (14\%) had other patterns. The proportion with normal spirometry increased from $65 \%$ at exam 1 to $85 \%$ at exam 2 in the persistent LRS group $(p<0.01)$ and was stable among asymptomatic participants and those with resolved LRS. By exam 2, spirometry results did not differ across symptom groups; however, $R_{5}$ and $\mathrm{R}_{5-20}$ abnormalities were more common among participants with persistent LRS ( $56 \%$ and $46 \%$, respectively) than among participants with resolved LRS (30\%, $p<0.01 ; 27 \%$, $\mathrm{p}=0.03)$ or asymptomatic participants $(20 \%, \mathrm{p}<0.001$; $8.2 \%, p<0.001)$. PTSD, $R_{5}$ at exam 1 , and $R_{5-20}$ at exam 1 were each independently associated with persistent LRS. Conclusions Peripheral airway dysfunction and PTSD may contribute to LRS persistence. Assessment of peripheral airway function detected pulmonary damage not evident on spirometry. Mental and physical healthcare for survivors of complex environmental disasters should be coordinated carefully.

\section{INTRODUCTION}

Lower respiratory symptoms (LRS) are among the most common sequelae of exposure to dust and fumes during the September 11, 2001 (9/11) World Trade Center (WTC) terrorist attacks and their aftermath. ${ }^{1-5}$ Although the pathophysiological processes associated with post-9/11-onset LRS remain under investigation, there is accumulating evidence of peripheral airway damage among many of those affected. $^{6-8}$ To investigate the relationship between

\section{What this paper adds}

- Many community members who were exposed to dust and fumes during the 9/11/2001 World Trade Center attacks have persistent lower respiratory symptoms (LRS), but little is known about underlying pulmonary function or risk factors for symptom persistence.

- In the current study, most participants with persistent post-9/11-onset LRS had abnormal impulse oscillometry results despite having normal screening spirometry, consistent with peripheral airway dysfunction.

- Peripheral airway dysfunction and 9/11-related post-traumatic stress disorder were each independently associated with the persistence of LRS 12-13 years after the attacks.

- These findings underscore the importance of coordinating mental and physical healthcare for survivors of complex environmental disasters and suggest that peripheral lung function assessment should be included in the evaluation of LRSs after such exposures.

peripheral airway function and post-9/11-onset LRS, we included impulse oscillometry (IOS) measurements in a 2008-2010 case-control study of LRS among 9/11-exposed community members. ${ }^{9}{ }^{10}$ We found that participants with LRS were more likely than asymptomatic controls to have had 9/11-related exposures in the home or workplace and to have abnormal spirometry and IOS. Among participants with normal spirometry, cases were more likely than controls to have abnormal IOS findings, consistent with peripheral airway damage. ${ }^{10}$

We and others have since documented the persistence of LRS among many 9/11-exposed persons $^{11-13}$ and have identified several factors that may cause or exacerbate LRS in this population. Among community members and local cleanup workers, persistent LRS were found to be associated with elevated markers of inflammation, including peripheral eosinophilia in those with wheezing ${ }^{14}$ and C-reactive protein in those with abnormal IOS, ${ }^{15}$ suggesting potential underlying mechanisms for the symptoms. There is also growing evidence that post-traumatic stress disorder (PTSD) is 
associated with both the presence and severity of LRS in 9/11exposed persons, ${ }^{16-19}$ with some indication that PTSD statistically mediates the relationship between 9/11 exposures and persistent LRS. $^{1718}$

We therefore conducted a follow-up study to describe the course of LRS among 9/11-exposed community members with LRS compared with those without LRS up to 13 years after the attacks. We also assessed the interrelationship among persistent LRS and pulmonary function abnormalities, including small airways dysfunction; ongoing airway inflammation, as reflected by fractional exhaled nitric oxide (FeNO); and PTSD.

\section{METHODS}

\section{Study population, recruitment and data collection}

The current study recruited participants from the 2008-2010 World Trade Center Health Registry case-control study. The Registry is a voluntary cohort of 71434 first responders, lower Manhattan area workers and residents, area school children and staff, and commuters and passersby who were directly exposed to the $9 / 11 / 2001$ WTC terrorist attacks, or participated in related rescue and recovery work. Participants completed an enrollment questionnaire in 2003-2004 (questionnaire 1) regarding 9/11related exposures, medical history and health status. In 20062007, 46602 adult enrollees (68\% of those eligible) completed the Registry's second questionnaire (questionnaire 2), which included questions about physical and mental health symptoms and diagnoses (see online supplementary table).

The case-control study (referred to subsequently as exam 1) recruited Registry participants who were aged $\geq 18$ years, resided or worked in Lower Manhattan on 9/11 and had completed questionnaires 1 and 2. Enrollees who performed 9/11 rescue/ recovery work, reported pre-9/11 LRS, had ever smoked cigarettes, lived $>50$ miles from New York City (NYC), had a history of respiratory or heart disease, were pregnant or were taking $\beta$-adrenergic blocking medication were excluded. The study enrolled 274 case-participants who reported LRS (persistent cough, shortness of breath or wheezing) on questionnaire 1 and the same LRS, or use of a physician-prescribed inhaler, on questionnaire 2, and 511 control participants who reported LRS on neither questionnaire. Participants completed computer-assisted, face-to-face interviews, anthropomorphic measurements and pulmonary function testing. Additional detail on exam 1, including a description of case and control selection, is available elsewhere. ${ }^{9} 10$

Exam 1 participants were then invited to return for a follow-up examination (exam 2). Exclusion criteria used at exam 1 were applied again at exam 2. During 2013-2014, participants completed a computer-assisted, interviewer-administered questionnaire, anthropomorphic measurements, spirometry, IOS and FeNO measurement at a lower Manhattan field site.

This study was approved by the NYC Department of Health and Mental Hygiene (IRB\# 07-32) and New York University School of Medicine (IRB i-13-00426) institutional review boards and was conducted in accordance with the amended Declaration of Helsinki. All participants provided written informed consent.

\section{Lower respiratory symptoms}

At both exam 1 and exam 2, LRS were defined as wheezing, dyspnoea or cough reported on $\geq 8$ of the 30 days preceding the interview or use of physician-prescribed medication for treatment of LRS. This definition was selected for consistency with the definition used in the original case-control study ${ }^{10}$ and other studies of post-9/11-onset LRS. ${ }^{12} 1315$

\section{Measures of pulmonary function}

Trained technicians conducted pulmonary function tests according to American Thoracic Society/European Respiratory Society standards ${ }^{20}$ using the same equipment at both exams (Masterscreen IOS, Viasys Healthcare, Yorba Linda, California). Spirometry measurements included the forced expiratory volume in $1 \mathrm{~s}\left(\mathrm{FEV}_{1}\right)$, the forced vital capacity (FVC) and the $\mathrm{FEV}_{1} / \mathrm{FVC}$. Data were referenced to the same published predictive equations used in exam 1 and were categorised as normal $\left(\mathrm{FEV}_{1} / \mathrm{FVC}\right.$ and $\mathrm{FVC} \geq$ fifth percentile), obstructive $\left(\mathrm{FEV}_{1} / \mathrm{FVC}\right.$ $<$ fifth percentile) or restrictive (FVC $<$ fifth percentile with normal $\mathrm{FEV}_{1} / \mathrm{FVC}$ ).

IOS measurements included resistance at an oscillating frequency of $5 \mathrm{~Hz}\left(\mathrm{R}_{5}\right)$ as a global measure of respiratory resistance. Resistance was further characterised by calculating the difference between $R_{5}$ and $R_{20}$ to quantify frequency dependence as a measure of peripheral airway function. ${ }^{21-23}$ To maintain consistency in interpretation of data over time, the values used for upper limits of normal were the same at exams 1 and $2\left(\mathrm{R}_{5}\right.$, $\left.3.96 \mathrm{~cm} \mathrm{H}_{2} \mathrm{O} / \mathrm{L} / \mathrm{s} ; \mathrm{R}_{5-20}, 0.76 \mathrm{~cm} \mathrm{H}_{2} \mathrm{O} / \mathrm{L} / \mathrm{s}\right)$. Although the same upper limits of normal were used for all subjects, these cutoffs are conservative estimates that approximate $150 \%$ of the mean values found in normal subjects. Data obtained in our laboratory on 80 asymptomatic non-smoking subjects with normal spirometry and without lung disease fell within these limits. In addition, the values for the selected upper limits of normal agree with estimates based on recent publications of normative data. ${ }^{24}$

Equipment was calibrated on each day of data collection. Spirometry and IOS testing procedures and data selection were consistent across exams. ${ }^{10}$

FeNO level was measured at exam 2 only, using a handheld device (NIOX MINO, Aerocrine AB, Solna, Sweden). At least two values were attempted per participant. Values were excluded from analysis if there was $>10 \%$ difference and an absolute difference of $>5 \mathrm{ppb}$ between the two most similar measurements. The two most similar FeNO values of acceptable quality (available for 454 participants) were averaged.

\section{Other measures}

Exposure to the massive dust cloud released when the WTC towers collapsed on the morning of 9/11 was defined as a participant's report of having such exposure on questionnaire 1, and also reporting having been at a geocodable location in lower Manhattan on the morning of $9 / 11 .{ }^{25}$ Composite scales from a previous analysis of exam 1 results $^{9}$ were used as measures of acute and chronic exposures to 9/11 dust in the home or workplace.

PTSD was assessed on the second Registry questionnaire and at exam 2 using the PTSD Checklist, a validated 17-item scale that inquired about 9/11-specific psychological symptoms during the 30 preceding days. ${ }^{26-28}$ Probable PTSD (subsequently called PTSD) was defined as a score $\geq 44$. $^{26}$

\section{Statistical analyses}

We used $\chi^{2}$ or Fisher's exact tests to assess the statistical significance of differences among participants with different LRS trajectories and the Kruskal-Wallis test to assess differences among distributions of continuous variables. The McNemar test was used to assess whether the proportion of participants with abnormal pulmonary physiology results differed at exam 1 versus exam 2. A p value of $<0.05$ was considered statistically significant. We used multivariable logistic regression to examine factors potentially associated with persistence of LRS. Because 

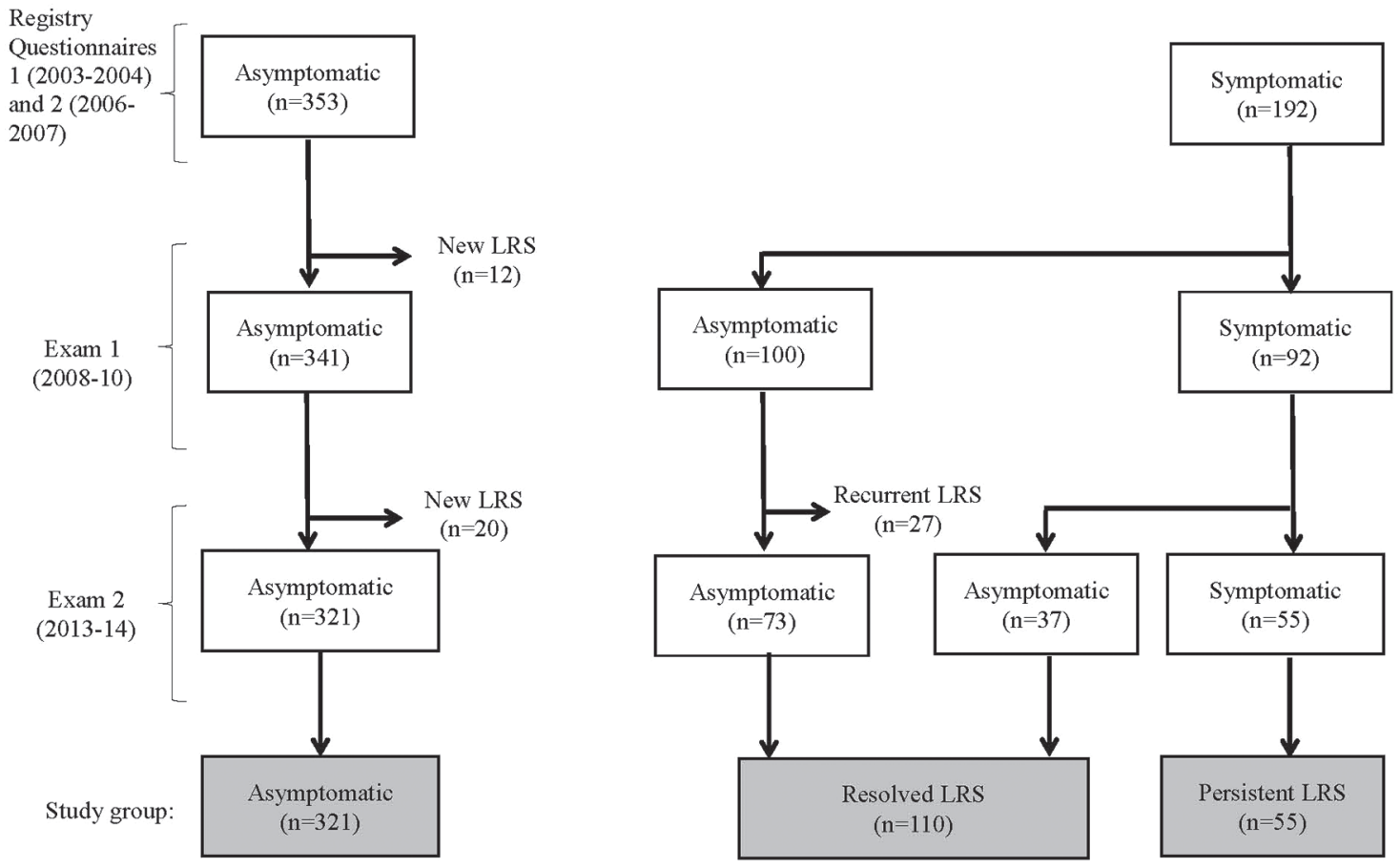

Figure 1 Patterns of lower respiratory symptoms (LRS) for 545 participants.

$\mathrm{R}_{5-20}$ is a component of $\mathrm{R}_{5}$, we fit separate models for each of these parameters. We used SAS software (V.9.4, SAS Institute, Cary, North Carolina, USA) for all analyses.

\section{RESULTS}

When exam 2 was launched (2013), three exam 1 participants had died, and three participants had withdrawn from the Registry. Of the remaining 779, 27 (3\%) were no longer eligible for study participation because they had begun smoking cigarettes, had moved $>50$ miles from NYC or met other exclusion criteria; 207 (27\%) declined; and 545 (70\%) participated between June 2013 and August 2014, a mean of 5.1 (range, 3.0-6.3) years after exam 1.

\section{Evolution of LRS}

Figure 1 shows the different courses of LRS symptoms between Registry enrollment and exam 2 for study participants. We focused the analysis on the most common trajectories identified: asymptomatic (without LRS at questionnaire 1, questionnaire 2, exam 1 and exam 2; $n=321$ ), resolved LRS (with LRS at questionnaires 1 and 2, but without LRS by the time of exam 2; $\mathrm{n}=110$ ) and persistent LRS (LRS present at all 4 assessments, $n=55)$. Participants with new-onset $(n=32)$ or recurrent LRS $(n=27)$ were not included in these analyses due to the small size of these groups. Among participants with persistent LRS at exam 2, the most common LRS reported during the month preceding the exam was cough $(70.9 \%)$, followed by shortness of breath $(63.6 \%)$, then wheezing $(49.1 \%)$.

\section{Characteristics of study participants}

Participants were primarily middle-aged, non-Hispanic white and highly educated (table 1). A higher proportion of participants with persistent LRS were female, black or Hispanic or had less than a college education compared with participants who were asymptomatic or had resolved LRS. The proportion of participants who were overweight or obese was higher among
Table 1 Characteristics of study participants according to symptom pattern

\begin{tabular}{|c|c|c|c|}
\hline \multirow[b]{3}{*}{ Characteristic } & Asymptomatic & Resolved LRS & Persistent LRS \\
\hline & $n=321$ & $\mathrm{n}=110$ & $n=55$ \\
\hline & $\% *$ & $\% *$ & $\% *$ \\
\hline Female sex & 52.3 & 62.7 & 78.2 \\
\hline \multicolumn{4}{|l|}{ Age on $9 / 11$ (years) } \\
\hline$<25$ & 10.0 & 2.7 & 1.8 \\
\hline $25-44$ & 54.8 & 58.2 & 50.9 \\
\hline $45-64$ & 34.0 & 36.4 & 45.5 \\
\hline $65+$ & 1.3 & 2.7 & 1.8 \\
\hline \multicolumn{4}{|l|}{ Race/ethnicity } \\
\hline non-Hispanic white & 76.0 & 58.2 & 38.2 \\
\hline Non-Hispanic black & 6.2 & 19.1 & 16.4 \\
\hline Hispanic & 4.4 & 10.0 & 27.3 \\
\hline Asian & 11.5 & 10.0 & 7.3 \\
\hline Multiracial and other races & 1.9 & 2.7 & 10.9 \\
\hline Education: college or higher & 85.7 & 74.6 & 50.9 \\
\hline \multicolumn{4}{|l|}{ BMl at exam 1} \\
\hline normal/low $(<25)$ & 57.3 & 33.6 & 21.8 \\
\hline Overweight (25-29.9) & 28.0 & 31.8 & 40.0 \\
\hline Obese $(\geq 30)$ & 13.7 & 34.6 & 38.2 \\
\hline \multicolumn{4}{|l|}{ Dust cloud exposure on 9/11 } \\
\hline No & 64.2 & 32.7 & 23.6 \\
\hline Yes & 31.5 & 64.6 & 65.5 \\
\hline PTSD (assessed 2006-2007) & 2.5 & 29.1 & 43.6 \\
\hline \multicolumn{4}{|c|}{$\begin{array}{l}\mathrm{p} \text { Value for } \chi^{2} \text { comparing patterns across three main symptom groups }<0.001 \text { for all } \\
\text { characteristics shown except age }(\mathrm{p}=0.07) \text {. } \\
\text { *Percentages may not sum up to } 100 \text { due to missing data. } \\
\text { †Defined as a PTSD checklist score } \geq 44 \text { on the } 2006-2007 \text { Registry questionnaire. } \\
\text { BMI, body mass index; LRS, lower respiratory symptoms; PTSD, post-traumatic } \\
\text { stress disorder. }\end{array}$} \\
\hline
\end{tabular}

those with persistent LRS than in the other groups, as was the proportion with exposure to the $9 / 11$ dust cloud. There was a 
gradient in the prevalence of PTSD across symptom trajectories, with the lowest prevalence among asymptomatic participants, intermediate prevalence among those with resolved LRS and highest prevalence among those with persistent LRS.

\section{Spirometry results}

Most participants had normal spirometry results at both exams (figure 2). Spirometry results did not change substantially between exams for asymptomatic participants or those with resolved LRS. Among participants with persistent LRS, however, the proportion with normal spirometry increased from $65 \%$ at exam 1 to $85 \%$ at exam $2(\mathrm{p}<0.01)$.

Because body mass index (BMI) can affect both LRS and spirometry, ${ }^{29}$ we assessed changes in BMI between exams. Median BMI increased between exams in all LRS symptom groups. Changes were similar for asymptomatic participants, those with resolved LRS and those with persistent LRS (median increase $0.26,0.62$ and $0.83 \mathrm{~kg} / \mathrm{m}^{2}$ between exams, respectively, Kruskal-Wallis test $\mathrm{p}$ value $=0.05$ ). Because an increase in BMI would be expected to cause worsening of, rather than improvement in, spirometry results, the observed changes in spirometry were not attributable to changes in BMI.

\section{Oscillometry results}

Between exams, the proportion of participants with abnormal $\mathrm{R}_{5}$ decreased significantly in all LRS groups (figure 3A). Nonetheless, at exam 2, $\mathrm{R}_{5}$ abnormalities remained among more than half (56\%) of participants with persistent LRS and were significantly more prevalent in this group than among participants with resolved LRS $(30 \%, \mathrm{p}<0.01)$ or asymptomatic participants $(20 \%, \mathrm{p}<0.001)$.

In contrast, there was little or no change in the prevalence of abnormal $\mathrm{R}_{5-20}$ between exam 1 and exam 2 within each LRS symptom group (figure $3 \mathrm{~B}$ ). However, the proportion of participants with abnormal $\mathrm{R}_{5-20}$ at exam 2 was higher among those with persistent LRS (46\%) than among those with resolved LRS $(27 \%, \mathrm{p}=0.03)$ or asymptomatic participants $(8 \%, \mathrm{p}<0.001)$.

\section{FeNO results}

Median FeNO values were similar for asymptomatic participants (20.5 ppb), those with resolved LRS (18.0 ppb) and those with persistent LRS (20.5 ppb; Kruskal-Wallis test $\mathrm{p}$ value $=0.13$ ). Using a cutoff of $>30 \mathrm{ppb}, 21.7 \%$ of participants with persistent LRS had elevated FeNO values, compared with $12.2 \%$ of participants with resolved LRS and $15.2 \%$ of asymptomatic participants $\left(\chi^{2}\right.$ test $p$ value 0.34$)$.

\section{Factors associated with LRS persistence}

To examine factors associated with the persistence of LRS, we conducted a subanalysis comparing participants with persistent LRS $(n=55)$ to those with resolved LRS $(n=110)$ at exam 2. In a multivariable analysis including 127 participants with complete data, $\mathrm{R}_{5}$ at exam 1 was associated with an increased odds of persistent LRS (adjusted OR (AOR) 1.79, 95\% CI 1.19 to 2.70), accounting for sex, education, BMI at exam 1, exposure to the dust cloud on 9/11, $\mathrm{FEV}_{1} \%$ predicted at exam 1 and PTSD on questionnaire 2 (table 2).

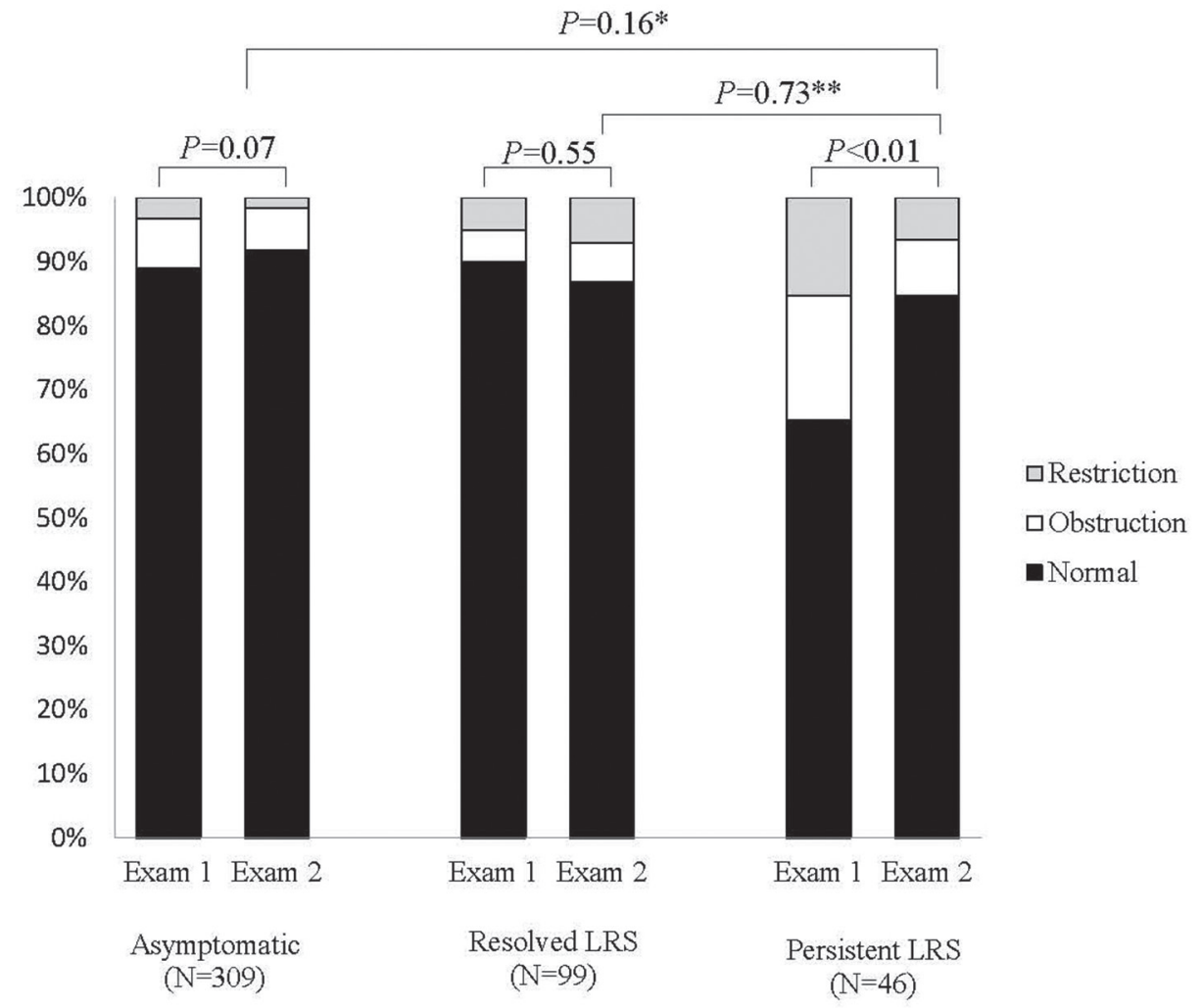

Figure 2 Spirometry patterns at exams 1 (2008-2010) and 2 (2013-2014) according to lower respiratory symptom pattern. Includes 454 participants with valid spirometry at both exams. $\chi^{2}$ or Fisher's exact tests were used to assess differences in the proportion with normal spirometry between symptom groups at exam 2. McNemar test was used to assess differences between exam 1 and exam 2 within each symptom group. ${ }^{*}$ Comparison of persistent versus asymptomatic groups at exam 2. ${ }^{*}$ Comparison of persistent versus resolved groups at exam 2. 


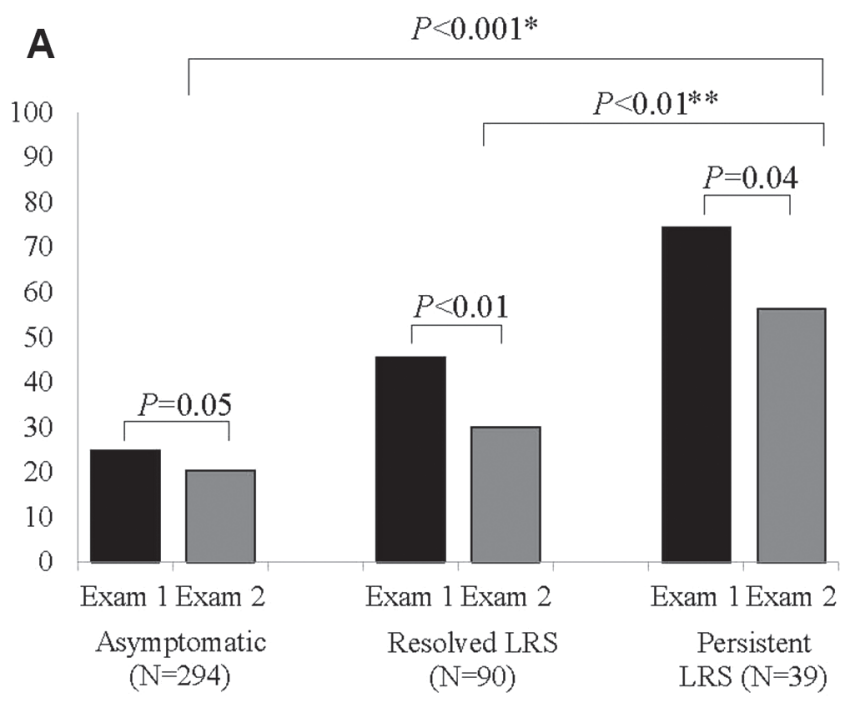

B

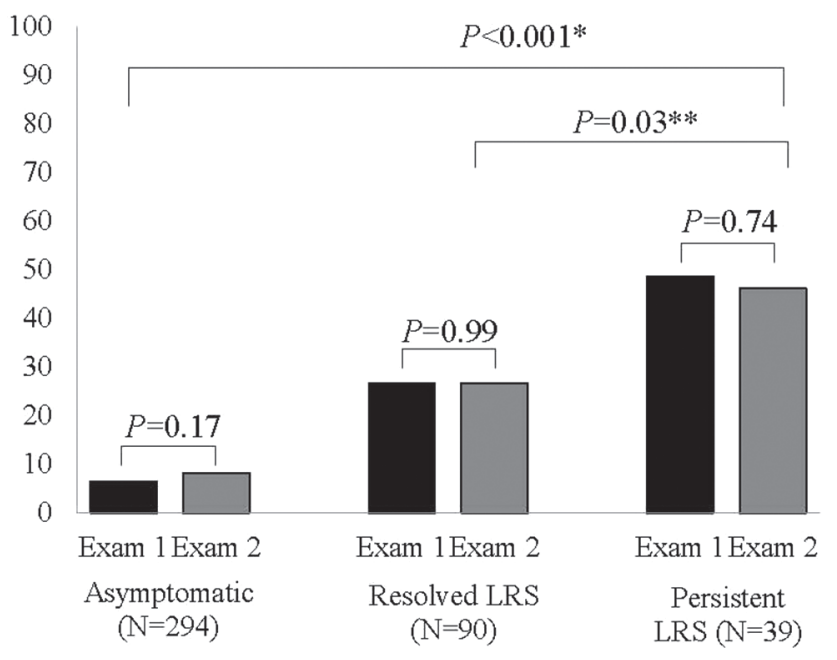

Figure 3 Percentage of participants with abnormal (A) $R_{5}$ and (B) $R_{5-20}$ at exam 1 (2008-2010) and exam 2 (2013-2014) according to lower respiratory symptom (LRS) pattern. Includes 423 participants with valid impulse oscillometry at both exams. $\chi^{2}$ test was used to assess difference between symptom groups at exam 2. McNemar test was used to assess differences between exam 1 and exam 2 within each symptom group. *Comparison of persistent versus asymptomatic groups at exam $2 .{ }^{* *}$ Comparison of persistent versus resolved groups at exam 2.

In a separate model controlling for the same factors, $R_{5-20}$ was also associated with an increased odds of persistent LRS (AOR $2.53,95 \% \mathrm{CI} 1.15$ to 5.57$)$. PTSD was independently associated with the persistence of LRS in both the $\mathrm{R}_{5}$ and the $\mathrm{R}_{5-20}$ models. Measures of 9/11-related exposure, including the 9/11 dust cloud (table 2) and the composite exposure variables (data not shown), were not significantly associated with LRS persistence.

\section{DISCUSSION}

We described the course of LRS and pulmonary function in a sample of community members enrolled in the WTC Health Registry. While most participants with post-9/11 LRS experienced symptom resolution during the study period, LRS persisted for a nearly one-third of those with initial symptoms. Most
Table 2 Multivariable logistic regression model of factors associated with persistent LRS at exam 2 compared with resolved LRS (reference group)

\begin{tabular}{|c|c|c|c|c|}
\hline \multirow[b]{2}{*}{ Characteristic } & \multicolumn{2}{|c|}{ Model 1: $\mathbf{R}_{5}$} & \multicolumn{2}{|c|}{ Model 2: $\mathbf{R}_{5-20}$} \\
\hline & $\mathrm{AOR}^{*}$ & $95 \% \mathrm{Cl}$ & $A O R^{*}$ & $95 \% \mathrm{Cl}$ \\
\hline Sex (F vs M) & 0.97 & (0.33 to 2.92$)$ & 1.70 & (0.63 to 4.61$)$ \\
\hline $\begin{array}{l}\text { Education (<college vs } \\
\geq \text { college) }\end{array}$ & 4.92 & (1.90 to 12.73 ) & 4.87 & (1.93 to 12.31$)$ \\
\hline PTSD at questionnaire 2 & 2.79 & (1.08 to 7.15$)$ & 2.60 & (1.03 to 6.55$)$ \\
\hline $\mathrm{BMI}$ at $\mathrm{R} 1^{\dagger}$ & 0.97 & (0.89 to 1.06 ) & 0.98 & (0.90 to 1.08$)$ \\
\hline $\begin{array}{l}\text { Exposure to 9/11 dust } \\
\text { cloud }\end{array}$ & 1.27 & (0.47 to 3.47 ) & 1.26 & (0.48 to 3.38 ) \\
\hline $\begin{array}{l}\mathrm{FEV}_{1} \% \text { predicted at } \\
{\text { Exam } 1^{+}}^{+}\end{array}$ & 1.00 & (0.97 to 1.04 ) & 1.00 & (0.97 to 1.03$)$ \\
\hline$R_{5}$ at exam $1 \neq$ & 1.79 & (1.19 to 2.70 ) & & \\
\hline $\mathrm{R}_{5-20}$ at exam $1 \neq$ & & & 2.53 & (1.15 to 5.57$)$ \\
\hline
\end{tabular}

$\mathrm{N}$ with complete data $=127$.

* Models are adjusted for all factors shown.

tModelled as a continuous variable in 10-point increments.

$¥$ Modelled as a continuous variable in $\mathrm{cm} \mathrm{H}_{2} \mathrm{O} / \mathrm{L} / \mathrm{s}$.

$A O R$, adjusted odds ratio; $\mathrm{BMI}$, body mass index; $\mathrm{FEV}_{1}$, forced expiratory volume in

$1 \mathrm{~s} ;$ PTSD, post-traumatic stress disorder.

(85\%) participants with persistent LRS had normal spirometry at follow-up; however, more than half had abnormal IOS results, including elevated resistance $\left(\mathrm{R}_{5}\right)$ and frequency dependence of resistance $\left(\mathrm{R}_{5-20}\right)$, suggesting that small airways dysfunction not detected on standard spirometry may underlie symptoms in this group. This was further supported by our finding that higher $\mathrm{R}_{5}$ and $\mathrm{R}_{5-20}$ values at exam 1 were associated with an increased odds of persistent LRS at follow-up. We also found evidence that PTSD was associated with symptom persistence.

Consistent with increases in FVC and $\mathrm{FEV}_{1}$ observed several years after 9/11 among non-smoking WTC Environmental Health Center patients, ${ }^{12}$ we found an improvement in spirometry among participants with persistent LRS. In contrast, the prevalence of abnormal $R_{5-20}$ in our study was relatively stable between exams. The improvement in spirometry may reflect resolution of 9/11-related central airway injuries, whereas the stability of $\mathrm{R}_{5-20}$ suggests there may be a sustained deficit in the peripheral airways of many participants with persistent LRS. These findings add to the evidence that small airways pathology contributes to post-9/11 LRS for many affected community members. ${ }^{6730}$

Although both acute and chronic exposure to dust resulting from 9/11 were risk factors for the onset of LRS in our initial case-control study ${ }^{9}$ and other investigations, ${ }^{45253132}$ these exposures were not associated with an increased risk of symptom persistence in the current study. It is possible that our study was underpowered to identify such an association; however, our results are compatible with the finding that, approximately 10 years after the attacks, 9/11-related exposures were not associated with the level of symptom control among Registry enrollees with post-9/11-onset asthma. ${ }^{33}$ Together, these findings suggest that although exposure was clearly associated with the onset of LRS, other factors have greater influence over the duration of such symptoms.

There is abundant evidence that PTSD and LRS are often comorbid among survivors of the WTC attacks. ${ }^{13} 16-1934$ Our finding that PTSD was associated with the persistence of LRS several years later suggests one potential explanation for this interrelationship. Although it is not possible to determine causality from this study, our results suggest that that treatment 
of psychological symptoms could play a role in the resolution of LRS as well.

Elevated FeNO is often used as a surrogate measure of airway allergic eosinophilic lung diseases, and low FeNO as a marker of neutrophilic inflammation. ${ }^{35}$ A previous study in WTC community members suggested an association between peripheral eosinophilia and wheezing, but not other LRS symptoms. ${ }^{14}$ Median FeNO levels in the current study were not elevated, suggesting that ongoing inflammation of this type is not a primary cause of persistent LRS in this study sample.

In our initial study, a higher BMI was associated with both an increased risk of LRS and the magnitude of IOS abnormalities. ${ }^{9}$ However, that study also found a relationship between LRS and IOS measures of peripheral airway dysfunction that was independent of BMI. In the current study, obesity did not play a significant role in the evolution of LRS or lung function, as BMI changed minimally between exams, including among participants with persistent LRS. Thus, although obesity may have influenced the initial development of LRS and degree of IOS abnormality at exam 1, neither the persistence of LRS nor the evolution of peripheral lung dysfunction between exams was attributable to changes in BMI.

Our results should be viewed in light of several limitations. Because participants were originally sampled for a case-control study, our findings cannot be used to estimate the prevalence of persistent LRS in the full population of 9/11-exposed community members. The size of the study sample, plus the availability of pulmonary function measurements at only two time points, limited our ability to conduct detailed statistical analyses of LRS and pulmonary function trajectories over time and to consider the patterns of specific LRS (cough, wheeze or dyspnoea) among participants. We did not have pulmonary imaging for participants. We also lacked access to medical records, and therefore were only able to gather limited, cross-sectional data on treatment at the time of the questionnaires and exams and none on treatment history or adherence. How medical treatment impacts LRS among persons exposed to $9 / 11$, especially those with comorbid psychological symptoms, is an important area for future studies.

Our study also has several strengths. Whereas other studies of LRS among 9/11-exposed community members drew from clinics that serve symptomatic patients, ours included an appropriate comparison group of 9/11-exposed community members without LRS, thereby providing information on pulmonary function across a broad spectrum of 9/11-exposed individuals.

\section{CONCLUSION}

This study extends previous evidence that peripheral airway abnormalities underlie persistent post-9/11-onset LRS for many of those affected, highlighting the role of peripheral airway function assessment after inhalational exposures. Our finding that PTSD may contribute to the persistence of LRS underscores the importance of considering both physical and mental health when assessing and treating survivors of complex environmental disasters and suggests that the efficacy of integrating physical and mental healthcare deserves additional study.

Acknowledgements The authors would like to acknowledge the essential contributions of the following individuals: Rafaela Cruzado, Joann Fields, Raymond Jimenez, Jaswinder Legha, Jiehui Li, Kimberly Mantilla, Jonathan Mcateer, Rhonda Regester, Joseph Slade, Daniel Wallingford, Margaret Wohlleber and David Wu.

Contributors HTJ had full access to all of the data in the study and takes responsibility for the integrity of the data and the accuracy of the data analysis. HTJ, SMF, JR, RMG, JEC, MRF, and KIB contributed substantially to the study design. HTJ, SMF, JR, RMG, SAM, FO, HA, YS, CM, JEC, MRF, and KIB contributed substantially to the data analysis and interpretation, and the writing of the manuscript.

Funding This publication was supported by Cooperative Agreement Numbers $2 \mathrm{U} 50 / \mathrm{OH} 009739$ and 5U50/OH009739 from the National Institute for Occupational Safety and Health (NIOSH) of the Centers for Disease Control and Prevention (CDC); U50/ATU272750 from the Agency for Toxic Substances and Disease Registry (ATSDR), CDC, which included support from the National Center for Environmental Health, CDC; and by the New York City Department of Health and Mental Hygiene (NYC DOHMH). Its contents are solely the responsibility of the authors and do not necessarily represent the official views of NIOSH, CDC or the Department of Health and Human Services.

Competing interests None declared.

Provenance and peer review Not commissioned; externally peer reviewed.

Open Access This is an Open Access article distributed in accordance with the Creative Commons Attribution Non Commercial (CC BY-NC 4.0) license, which permits others to distribute, remix, adapt, build upon this work non-commercially, and license their derivative works on different terms, provided the original work is properly cited and the use is non-commercial. See: http://creativecommons.org/ licenses/by-nc/4.0/

(c) Article author(s) (or their employer(s) unless otherwise stated in the text of the article) 2017. All rights reserved. No commercial use is permitted unless otherwise expressly granted.

\section{REFERENCES}

1 Wisnivesky JP, Teitelbaum SL, Todd AC, et al. Persistence of multiple illnesses in worldtrade center rescue and recovery workers: a cohort study. Lancet 2011;378:888-97.

2 Lin S, Jones R, Reibman J, et al. Lower respiratory symptoms among residents living near the world trade center, two and four years after 9/11. Int J Occup Environ Health 2010;16:44-52.

3 Prezant DJ, Weiden M, Banauch Gl, et al. Cough and bronchial responsiveness in firefighters at the world trade center site. N Eng/ J Med 2002;347:806-15.

4 Farfel M, DiGrande L, Brackbill R, et al. An overview of 9/11 experiences and respiratory and mental health conditions among world trade center health registry enrollees. J Urban Health 2008;85:880-909.

5 Reibman J, Lin S, Hwang SA, et al. The world trade center residents' respiratory health study: new-onset respiratory symptoms and pulmonary function. Environ Health Perspect 2005;113:406-11.

6 Oppenheimer BW, Goldring RM, Herberg ME, et al. Distal airway function in symptomatic subjects with normal spirometry following world trade center dust exposure. Chest 2007;132:1275-82.

7 Berger $\mathrm{KI}$, Turetz $\mathrm{M}$, Liu M, et al. Oscillometry complements spirometry in evaluation of subjects following toxic inhalation. ERJ Open Res 2015;1:00043-2015.

8 Caplan-Shaw CE, Yee $\mathrm{H}$, Rogers L, et al. Lung pathologic findings in a local residential and working community exposed to world trade center dust, gas, and fumes. J Occup Environ Med 2011;53:981-91.

9 Maslow CB, Friedman SM, Pillai PS, et al. Chronic and acute exposures to the world trade center disaster and lower respiratory symptoms: area residents and workers. Am J Public Health 2012;102:1186-94.

10 Friedman SM, Maslow CB, Reibman J, et al. Case-control study of lung function in world trade center health registry area residents and workers. Am J Respir Crit Care Med 2011;184:582-9.

11 Weakley J, Webber MP, Gustave J, et al. Trends in respiratory diagnoses and symptoms of firefighters exposed to the world trade center disaster: 2005-2010. Prev Med 2011;53:364-9.

12 Liu M, Qian M, Cheng Q, et al. Longitudinal spirometry among patients in a treatment program for community members with world trade Center-related illness. J Occup Environ Med 2012;54:1208-13.

13 Friedman SM, Farfel MR, Maslow C, et al. Risk factors for and consequences of persistent lower respiratory symptoms among world trade center health registrants 10 years after the disaster. Occup Environ Med 2016;73:676-84.

14 Kazeros A, Maa MT, Patrawalla P, et al. Elevated peripheral eosinophils are associated with new-onset and persistent wheeze and airflow obstruction in world trade center-exposed individuals. J Asthma 2013;50:25-32.

15 Kazeros A, Zhang E, Cheng X, et al. Systemic inflammation associated with world trade center dust exposures and airway abnormalities in the local community. J Occup Environ Med 2015;57:610-6.

16 Friedman SM, Farfel MR, Maslow CB, et al. Comorbid persistent lower respiratory symptoms and posttraumatic stress disorder 5-6 years post-9/11 in responders enrolled in the world trade center health registry. Am J Ind Med 2013:56:1251-61.

17 Kotov R, Bromet EJ, Schechter C, et al. Posttraumatic stress disorder and the risk of respiratory problems in world trade center responders: Iongitudinal test of a pathway. Psychosom Med 2015;77:438-48. 
18 Luft BJ, Schechter C, Kotov R, et al. Exposure, probable PTSD and lower respiratory illness among world trade center rescue, recovery and clean-up workers. Psychol Med 2012;42:1069-79.

19 Niles JK, Webber MP, Gustave J, et al. Comorbid trends in world trade center cough syndrome and probable posttraumatic stress disorder in firefighters. Chest 2011;140:1146-54.

20 Miller MR, Hankinson J, Brusasco V, et al; ATS/ERS Task Force. Standardisation of spirometry. Eur Respir J 2005;26:319-38.

21 Bates JH, Lutchen KR. The interface between measurement and modeling of peripheral lung mechanics. Respir Physio/ Neurobiol 2005;148:153-64.

22 Fredberg JJ, Mead J. Impedance of intrathoracic airway models during low-frequency periodic flow. J Appl Physiol Respir Environ Exerc Physiol 1979;47:347-51.

23 Goldman MD, Saadeh C, Ross D. Clinical applications of forced oscillation to assess peripheral airway function. Respir Physiol Neurobiol 2005;148:179-94.

24 Oostveen E, Boda K, van der Grinten CP, et al. Respiratory impedance in healthy subjects: baseline values and bronchodilator response. Eur Respir J 2013;42:1513-23.

25 Brackbill RM, Hadler JL, DiGrande L, et al. Asthma and posttraumatic stress symptoms 5 to 6 years following exposure to the world trade center terrorist attack. JAMA 2009;302:502-16.

26 Blanchard EB, Jones-Alexander J, Buckley TC, et al. Psychometric properties of the PTSD checklist (PCL). Behav Res Ther 1996;34:669-73.

27 Ventureyra VA, Yao SN, Cottraux J, et al. The validation of the posttraumatic stress disorder checklist scale in posttraumatic stress disorder and nonclinical subjects. Psychother Psychosom 2002;71:47-53.
28 Weathers FW, Litz BT, Herman DS, et al. The PTSD checklist (PCL): Reliability, validity, and diagnostic utility, San Antonio, TX. 9th Annual Conference of the ISTSS, 1993.

29 Skloot GS, Schechter CB, Herbert R, et al. Longitudinal assessment of spirometry in the world trade center medical monitoring program. Chest 2009;135:492-8.

30 Berger KI, Reibman J, Oppenheimer BW, et al. Lessons from the world trade center disaster: airway disease presenting as restrictive dysfunction. Chest 2013;144:249-57.

31 Lin S, Reibman J, Bowers JA, et al. Upper respiratory symptoms and other health effects among residents living near the world trade center site after September 11, 2001. Am J Epidemio/ 2005;162:499-507.

32 Lin S, Jones R, Reibman J, et al. Reported respiratory symptoms and adverse home conditions after 9/11 among residents living near the world trade center. J Asthma 2007; 44:325-32.

33 Jordan HT, Stellman SD, Reibman J, et al. Factors associated with poor control of 9/11-related asthma 10-11 years after the 2001 world trade center terrorist attacks. J Asthma 2015;52:630-7.

34 Nair HP, Ekenga CC, Cone JE, et al. Co-occurring lower respiratory symptoms and posttraumatic stress disorder 5 to 6 years after the world trade center terrorist attack. Am J Public Health 2012;102:1964-73.

35 Dweik RA, Boggs PB, Erzurum SC, et al; American Thoracic Society Committee on Interpretation of Exhaled Nitric Oxide Levels (FENO) for Clinical Applications. An official ATS clinical practice guideline: interpretation of exhaled nitric oxide levels (FENO) for clinical applications. Am J Respir Crit Care Med 2011;184:602-15.

36 Spahn JD, Malka J, Szefler SJ. Current application of exhaled nitric oxide in clinical practice. J Allergy Clin Immunol 2016;138:1296-8. 